\title{
Impact of left ventricular function on immediate and long-term outcomes after pericardiectomy in constrictive pericarditis
}

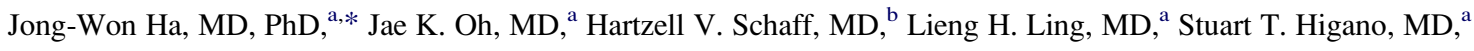 \\ Doug W. Mahoney, MS, ${ }^{\mathrm{c}}$ and Rick A. Nishimura, $\mathrm{MD}^{\mathrm{a}}$
}

\begin{abstract}
Objective: Most patients with constrictive pericarditis have normal measures of left ventricular function when assessed by the ejection phase index of ejection fraction, yet there is a wide spectrum of outcome after pericardiectomy. We hypothesized that parameters of non-ejection indexes of cardiac function $(+\mathrm{dP} / \mathrm{dt}$ and tau $)$ may predict postoperative prognosis.
\end{abstract}

\begin{abstract}
Methods: The immediate and long-term outcomes of pericardiectomy were analyzed in 40 patients (30 male, mean age 62 years) with surgically confirmed constrictive pericarditis who underwent preoperative cardiac catheterization using high-fidelity micromanometer pressures. Left ventricular pressures were digitized at 5-msec intervals during end expiration, from which peak positive dp/dt and tau measurements were obtained. Patients were classified into 3 groups: Group $1(\mathrm{n}=13)$ included those with abnormal $+\mathrm{dP} / \mathrm{dt}$ and tau (defined as $+\mathrm{dP} / \mathrm{dt}<1200 \mathrm{~mm} \mathrm{Hg} / \mathrm{s}$, tau $>50 \mathrm{msec})$; group $2(\mathrm{n}=11)$ included those with either abnormal $+\mathrm{dP} / \mathrm{dt}$ or tau; and group $3(\mathrm{n}=16)$ included those with normal $+\mathrm{dP} / \mathrm{dt}$ and tau.

Results: There were no significant differences of gender, New York Heart Association class, duration of symptoms, and underlying cause among the 3 groups. Group 1 patients had lower preoperative ejection fraction and higher left and right ventricular end-diastolic pressures. Postoperative inotropic support was more frequently needed in group 1, and postoperative mortality was higher in group 1 than in groups 2 and 3 . All postoperative deaths but 1 were in group 1. The median postoperative follow-up was 2.4 years. The postoperative long-term survival of group 1 was significantly lower compared with that of groups 2 and 3.
\end{abstract}

Conclusion: In patients with constrictive pericarditis undergoing pericardiectomy, those with abnormal left ventricular contractility and relaxation properties assessed by cardiac catheterization before surgery incur higher operative mortality and poor long-term outcome after surgery.

Constrictive pericarditis $(\mathrm{CP})$ is an inflammatory process of the pericardium, leading to a thickened, scarred, and often calcified pericardium that limits diastolic ventricular filling. Because the fundamental abnormality in CP is limited filling and enhanced interventricular dependence of the heart because of the rigid encasement of the heart, the myocardium should be intrinsically normal with no specific abnormality of systolic or diastolic function. Pericardiectomy is the only accepted curative treatment for $\mathrm{CP}$, and large series have demonstrated its efficacy. ${ }^{1-5}$ However, there have always been some early deaths because of low output syndrome after pericardiectomy, ${ }^{2,6,7}$ regardless of the operative approach or extent of pericardial resection. The pathophysiologic mechanisms of perioperative death after pericardiectomy are not well characterized. Several mechanisms have been suggested: immobilization atrophy, myopericardial

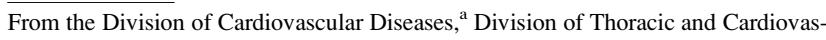
cular Surgery, ${ }^{\mathrm{b}}$ and Section of Biostatistics, ${ }^{\mathrm{c}}$ Mayo Clinic, Rochester, Minn.

* Dr Ha's current affiliation is the Cardiology Division, Yonsei University College of Medicine, Seoul, South Korea.

Received for publication March 31, 2006; revisions received Feb 13, 2008; accepted for publication March 30, 2008.

Address for reprints: Jae K. Oh, MD, Mayo Clinic, 200 First Street, SW, Rochester, MN 55905.

J Thorac Cardiovasc Surg 2008; 136:1136-41

$0022-5223 / \$ 34.00$

Copyright (c) 2008 by The American Association for Thoracic Surgery doi: $10.1016 /$ j.jtcvs. 2008.03 .065 involvement by the same pathologic process (exemplified by radiation disease), or physical extension of pericardial calcification into the myocardium. ${ }^{8-11}$ Thus, intrinsic myocardial property, which can be assessed by cardiac catheterization, may be an important determinant of postoperative outcome. Because there is a wide spectrum of outcome after pericardiectomy despite normal measures of left ventricular (LV) function assessed by the ejection phase index of ejection fraction, we hypothesized that parameters of nonejection indexes of cardiac function $(+\mathrm{dP} / \mathrm{dt}$ and tau) may predict postoperative prognosis. The purpose of this study was, therefore, to evaluate the impact of parameters reflecting LV contractility and relaxation property assessed by cardiac catheterization $(+\mathrm{dP} / \mathrm{dt}$ and tau $)$ on the postoperative prognosis in patients undergoing pericardiectomy.

\section{MATERIALS AND METHODS \\ Study Population}

All patients with the diagnosis of $\mathrm{CP}$ in the medical and surgical indexes of the Mayo Clinic from March of 1994 to October of 1998 were screened. Only patients with CP confirmed at surgery or autopsy who had cardiac catheterization with a micromanometer catheter were included. Case histories were reviewed, and clinical findings by a staff cardiologist were recorded. Follow-up of patients was done with a mailed questionnaire, hospital records, and telephone calls to the patients, their relatives, and their physicians. The circumstances and causes of death recorded in death certificates were verified whenever possible with the patient's physician or the coroner who certified the death. Patients were classified, according to 


\section{Abbreviations and Acronyms \\ $\mathrm{CHF}=$ congestive heart failure \\ $\mathrm{CP}=$ constrictive pericarditis \\ $\mathrm{LV}=$ left ventricular}

parameters of non-ejection indexes of cardiac function ( $\mathrm{dP} / \mathrm{dt}$ and tau), into 3 groups: Group $1(\mathrm{n}=13)$ included those with abnormal $+\mathrm{dP} / \mathrm{dt}$ and tau, defined as $+\mathrm{dP} / \mathrm{dt}$ less than $1200 \mathrm{~mm} \mathrm{Hg} / \mathrm{s}$ and tau greater than $50 \mathrm{msec}$; group $2(\mathrm{n}=11)$ included those with either abnormal $+\mathrm{dP} / \mathrm{dt}$ or tau; and group $3(n=16)$ included those with normal $+\mathrm{dP} / \mathrm{dt}$ and tau. This study was approved by the Mayo Foundation Institutional Review Board.

\section{Echocardiography}

Two-dimensional and Doppler echocardiographic examinations were performed in a standard manner with a commercially available cardiac ultrasound unit. A pulsed-wave Doppler study of mitral inflow velocity and hepatic vein velocity was performed with simultaneous respiratory recording with a nasal thermistor, as described previously. ${ }^{12,13}$ The first cardiac cycles in which filling and ejection occurred in their entirety during a particular respiratory phase (either inspiration or expiration) were analyzed. Three respiratory cycles were analyzed for the patients. All Doppler velocities were recorded with a sweep speed of 50 or $100 \mathrm{~mm} / \mathrm{s}$. The percentage of respiratory changes in E velocity was calculated as [(expiratory E - inspiratory E)/ inspiratory E] $\times 100 \%$.

\section{Cardiac Catheterization}

Cardiac catheterization was performed with the patient in the fasting state. A femoral venous and arterial access site was used in all patients. Patients were sedated with midazolam, fentanyl, or both. All patients received $5000 \mathrm{U}$ of heparin administered intravenously at the start of the procedure. High-fidelity micromanometer-tipped catheters (Millar Instruments, Inc, Houston, Tex) were used to obtain right- and left-sided heart pressure waveforms. One of 2 techniques was performed for measurement of the left-sided heart pressures. In the first technique, a 7F fluid-filled pigtail catheter was advanced retrogradely into the left ventricle. A $2 \mathrm{~F}$ high-fidelity catheter was introduced through the lumen of the pigtail catheter and advanced to its distal orifice. The high-fidelity pressures were zeroed and balanced to the end-diastolic and peak systolic pressures of the fluid-filled system, as described previously in our laboratory. ${ }^{14} \mathrm{~A}$ second technique used a 7F pigtail catheter with both a fluid-filled end-hole lumen and a side-mounted high-fidelity sensor. The same calibration procedure for the high-fidelity pressures was performed as described above. The measure of contractility used in this study was the peak positive rate of increase of $\mathrm{LV}$ pressure $(+\mathrm{dP} / \mathrm{dt})$. The measure of relaxation was the time constant of isovolumic LV relaxation (tau). Right-sided heart catheterization was performed with a 7F balloon-tipped, large-lumen pulmonary wedge catheter, or $7 \mathrm{~F}$ end-hole catheter. The catheter was advanced into the pulmonary tree until a pulmonary wedge contour was observed. Confirmation of the wedge position was obtained with an oxygen saturation more than $95 \%$. A $2 \mathrm{~F}$ high-fidelity micromanometer-tipped catheter was then inserted into the fluid-filled catheter, and the high-fidelity pressures were balanced against the fluid-filled pressures. For measurement of right-sided heart pressures in all chambers, the rightsided heart catheter was pulled back sequentially into the pulmonary artery, right ventricle, and mid-right atrium. For each chamber, the high-fidelity pressures were rebalanced to the fluid-filled pressures. For the 14 patients in atrial fibrillation, a temporary pacemaker was placed to obtain a regular rhythm. For this, a second 7F sheath was introduced into the right femoral vein, and a 7F monophasic temporary pacing lead was advanced into the right ventricular apex. Adequate positioning was confirmed by fluoroscopic guidance, as well as by obtaining a pacing threshold of less than $2 \mathrm{~mA}$. The pacing rate was set 10 beats/min higher than the resting heart rate to ensure continuous pacing. All pressure recordings and the respirometer tracings were recorded on paper at 25,50 , and $100 \mathrm{~mm} / \mathrm{s}$ for at least 1 minute at each speed during normal respirations.

\section{Statistical Analysis}

Categoric data, expressed as percentages, were compared by the chisquare test. Continuous variables, expressed as mean \pm standard deviation, were compared by the 2-sample Wilcoxon rank-sum test. The rates of allcause mortality were estimated by the Kaplan-Meier method. Late survival curves were compared with those of a normal 1990 US population matched for age and sex by the log-rank test. Postoperative creatinine elevation was defined as an increase in serum creatinine concentration of $0.5 \mathrm{mg} / \mathrm{dL}$ from preoperative values. Postoperative creatinine values were measured within 48 hours or before dismissal. Perioperative death was defined as that occurring within 30 days after surgery. However, all deaths within the same hospitalization as for surgery were included in analysis of perioperative death. Cardiac-related death was defined as death due to cardiac causes, such as progressive congestive heart failure (CHF) or sudden death. Sudden unexpected death was defined according to the criteria of Hinkle and Thaler, ${ }^{15}$ whereas sudden expected death was abrupt death occurring in the setting of progressive $\mathrm{CHF}$ or an episode of CHF in the preceding 12 months. To evaluate the incremental prognostic value of non-ejection indexes of cardiac function $(+\mathrm{dP} / \mathrm{dt}$ and tau), the global log likelihood ratio chi-square statistics for models developed using 1) ejection fraction, LV end-diastolic pressure, or right ventricular end-diastolic pressure alone and 2) ejection fraction, LV end-diastolic pressure, or right ventricular end-diastolic pressure plus nonejection indexes of cardiac function $(+\mathrm{dP} / \mathrm{dt}$ and tau) were determined by Cox proportional hazards regression and depicted graphically.

\section{RESULTS}

\section{Clinical Characteristics, Doppler \\ Echocardiographic, and Catheterization Findings}

Clinical characteristics of the study population are shown in Table 1. For pericardiectomy, a median sternotomy was performed in 25 patients, a lateral thoracotomy was performed in 8 patients, and a bilateral thoracotomy was performed in 7 patients. There were no significant differences in gender, New York Heart Association (NYHA) class, duration of symptoms, and underlying cause among the 3

TABLE 1. Comparison of clinical variables

\begin{tabular}{lcccc}
\hline & $\begin{array}{c}\text { Group 1 } \\
(\mathbf{n}=\mathbf{1 3})\end{array}$ & $\begin{array}{c}\text { Group 2 } \\
(\mathbf{n = 1 1 )}\end{array}$ & $\begin{array}{c}\text { Group 3 } \\
(\mathbf{n}=\mathbf{1 6})\end{array}$ & $\begin{array}{c}\boldsymbol{P} \\
\text { value }\end{array}$ \\
\hline Age (y) & $67 \pm 12$ & $54 \pm 13$ & $63 \pm 11$ & .04 \\
Gender (M/F) & $12 / 1$ & $8 / 3$ & $10 / 6$ & .14 \\
NYHA class & & & & \\
$\quad 2$ & 2 & 0 & 6 & .09 \\
3 & 7 & 8 & 6 & \\
$\quad 4$ & 4 & 3 & 4 & \\
Symptom duration (d) & $591 \pm 402$ & $1179 \pm 1229$ & $963 \pm 269$ & .40 \\
Cause & & & & \\
$\quad$ Previous cardiac & 7 & 5 & 3 & .11 \\
$\quad$ surgery & & & & \\
$\quad$ Radiation-induced & 1 & 2 & 2 & .74 \\
$\quad$ Idiopathic & 4 & 1 & 5 & .31 \\
$\quad$ Others & 1 & 3 & 6 & \\
Ejection fraction (\%) & $49 \pm 12$ & $58 \pm 11$ & $60 \pm 8$ & .02 \\
\hline
\end{tabular}

NYHA, New York Heart Association. 
TABLE 2. Left ventricular filling parameters

\begin{tabular}{lcccc}
\hline & $\begin{array}{c}\text { Group 1 } \\
(\mathbf{n}=\mathbf{1 3})\end{array}$ & $\begin{array}{c}\text { Group 2 } \\
(\mathbf{n}=\mathbf{1 1})\end{array}$ & $\begin{array}{c}\text { Group 3 } \\
(\mathbf{n}=\mathbf{1 6})\end{array}$ & $\begin{array}{c}\boldsymbol{P} \\
\text { value }\end{array}$ \\
\hline E ins (m/s) & $0.69 \pm 0.28$ & $0.72 \pm 0.27$ & $0.82 \pm 0.36$ & .59 \\
E exp (m/s) & $0.94 \pm 0.33$ & $0.93 \pm 0.24$ & $1.0 \pm 0.33$ & .84 \\
Resp variation (\%) & $40 \pm 28$ & $35 \pm 17$ & $27 \pm 22$ & .42 \\
A ins (m/s) & $0.32 \pm 0.40$ & $0.43 \pm 0.32$ & $0.31 \pm 0.26$ & .76 \\
A exp (m/s) & $0.31 \pm 0.36$ & $0.49 \pm 0.34$ & $0.36 \pm 0.28$ & .58 \\
DT ins (ms) & $135 \pm 48$ & $128 \pm 22$ & $128 \pm 39$ & .92 \\
DT exp (ms) & $158 \pm 39$ & $150 \pm 39$ & $154 \pm 42$ & .92 \\
\hline
\end{tabular}

$E$, Mitral early diastolic filling velocity; Ins, inspiration; Exp, expiration; $A$, mitral late diastolic filling velocity; $D T$, deceleration time of $\mathrm{E}$ wave.

groups. However, history of coronary artery bypass graft surgery was more common in group 1 . Patients in group 2 were younger than patients in groups 1 and 3. Patients in group 1 had lower preoperative ejection fraction compared with those of groups 2 and 3. There were no significant differences in LV filling parameters by Doppler echocardiography among the 3 groups (Table 2). Right atrial, right ventricular end-diastolic and LV end-diastolic pressures, and tau were higher in groups 1 and 2 compared with those of group 3 (Table 3 ).

\section{Postoperative Outcome}

The total hospital stay of group 1 ( $16 \pm 11$ days) was longer compared with that of group 2 (13 \pm 8 days) or group 3 (12 \pm 9 days). Postoperative creatinine elevation was more common in group 1 (5 patients) compared with that of group 2 (2 patients) or group 3 (1 patient). Postoperative inotropic support was required in 3 patients, and intraaortic balloon pump was required in 2 patients. All of these patients were from group 1. The 30-day perioperative mortality was $15 \%(6 / 40)$; of these 6 patients, 5 were from group 1 and 1 was from group 2 . No patients of group 3 died postoperatively. The principal causes of death were low output state in 5 patients and sudden death in 1 patient. Of these, pericardiectomy was complete in 5 patients and partial in 1 patient (Table 4).

There were no significant differences in age, gender, NYHA class, duration of symptoms, underlying cause, and

TABLE 3. Catheterization data

\begin{tabular}{lcccc}
\hline & $\begin{array}{c}\text { Group 1 } \\
(\mathbf{n}=\mathbf{1 3})\end{array}$ & $\begin{array}{c}\text { Group 2 } \\
(\mathbf{n}=\mathbf{1 1})\end{array}$ & $\begin{array}{c}\text { Group 3 } \\
(\mathbf{n}=\mathbf{1 6})\end{array}$ & $\begin{array}{c}\boldsymbol{P} \\
\text { value }\end{array}$ \\
\hline Mean RAP (mm Hg) & $25 \pm 5$ & $24 \pm 5$ & $19 \pm 7$ & .04 \\
RVSP (mm Hg) & $49 \pm 7$ & $46 \pm 10$ & $45 \pm 9$ & .5 \\
RVEDP (mm Hg) & $27 \pm 6$ & $25 \pm 7$ & $20 \pm 6$ & .02 \\
PASP (mm Hg) & $48 \pm 7$ & $46 \pm 11$ & $45 \pm 8$ & .57 \\
PADP (mm Hg) & $28 \pm 6$ & $28 \pm 8$ & $24 \pm 5$ & .2 \\
PAWP (mm Hg) & $29 \pm 6$ & $29 \pm 9$ & $23 \pm 7$ & .09 \\
LVSP (mm Hg) & $116 \pm 28$ & $120 \pm 26$ & $124 \pm 20$ & .69 \\
LVEDP (mm Hg) & $30 \pm 5$ & $28 \pm 8$ & $23 \pm 5$ & .02 \\
tdP/dt (mm Hg/sec) & $979 \pm 188$ & $1324 \pm 113$ & $1531 \pm 292$ & $<.0001$ \\
tau (msec) & $75 \pm 12$ & $62 \pm 14$ & $42 \pm 6$ & $<.0001$ \\
\hline
\end{tabular}

TABLE 4. Postoperative outcomes

\begin{tabular}{|c|c|c|c|c|}
\hline & $\begin{array}{l}\text { Group 1 } \\
(\mathbf{n}=13)\end{array}$ & $\begin{array}{l}\text { Group 2 } \\
(\mathbf{n}=11)\end{array}$ & $\begin{array}{l}\text { Group 3 } \\
(\mathbf{n}=16)\end{array}$ & $\begin{array}{c}P \\
\text { value }\end{array}$ \\
\hline $\begin{array}{l}\text { Postoperative RA } \\
\text { pressure }(\mathrm{mm} \mathrm{Hg})\end{array}$ & $11 \pm 5$ & $10 \pm 2$ & $10 \pm 4$ & .75 \\
\hline Postoperative CI $\left(\mathrm{L} / \mathrm{min} / \mathrm{m}^{2}\right)$ & $2.7 \pm 0.9$ & $2.9 \pm 0.5$ & $3.2 \pm 0.7$ & .34 \\
\hline $\begin{array}{l}\text { Postoperative creatinine } \\
\text { elevation }\end{array}$ & 5 & 2 & 1 & .09 \\
\hline $\begin{array}{l}\text { Postoperative inotropic } \\
\text { support }\end{array}$ & 3 & 0 & 0 & .03 \\
\hline Postoperative IABP & 2 & 0 & 0 & \\
\hline Total hospital stay (d) & $16 \pm 11$ & $13 \pm 8$ & $12 \pm 9$ & .53 \\
\hline Operative mortality & 5 & 1 & 0 & .01 \\
\hline
\end{tabular}

ejection fraction between the 2 groups (Table 5). LV filling parameters by Doppler echocardiography was not significantly different between the 2 groups (Table 6). Right and LV end-diastolic pressures and tau were higher and cardiac index was significantly lower in patients with perioperative mortality compared with those without perioperative mortality (Table 7). Postoperative inotropic support was required in 3 patients, all of whom were from group 1 and died postoperatively. The predictive power for operative mortality, based on the global model chi-square value, was improved significantly with the addition of non-ejection indexes of cardiac function $(+\mathrm{dP} / \mathrm{dt}$ and tau) to ejection fraction, left ventricular end-diastolic pressure, or right ventricular enddiastolic pressure alone (Figures 1-3).

\section{Late Outcomes}

At last follow-up, 24 of the 34 operative survivors (71\%) were alive. The median postoperative follow-up was 2.4 years. The late deaths in 10 patients resulted from cardiac-related causes in 2 patients, pulmonary disease in 4 patients, noncardiac illness in 2 patients, and sudden death in 2

TABLE 5. Comparion of clinical variables between patients with or without operative mortality

\begin{tabular}{lccc}
\hline & $\begin{array}{c}\text { Op mortality }(-) \\
(\mathbf{n}=\mathbf{3 4})\end{array}$ & $\begin{array}{c}\text { Op mortality }(+) \\
(\mathbf{n}=\mathbf{6})\end{array}$ & $\begin{array}{c}\boldsymbol{P} \\
\text { value }\end{array}$ \\
\hline Age (years) & $62 \pm 12$ & $62 \pm 12$ & 0.86 \\
Gender (M/F) & $25 / 9$ & $5 / 1$ & 0.52 \\
NYHA class & & & 0.16 \\
$\quad 2$ & 8 & - & \\
3 & 18 & 3 & \\
$\quad 4$ & 8 & 3 & \\
symptom duration (days) & $923 \pm 1090$ & $780 \pm 443$ & 0.77 \\
Etiology & & & \\
$\quad$ idiopathic & 8 & 2 & 0.62 \\
$\quad$ previous cardiac surgery & 12 & 3 & 0.5 \\
$\quad$ radiation-induced & 4 & 1 & 0.75 \\
$\quad$ Others & 10 & & \\
LV ejection fraction $(\%)$ & $57 \pm 9$ & $47 \pm 18$ & 0.03 \\
post-op inotropic support & 0 & 3 & $<.0005$ \\
\hline$M$, denotes male; $F$, female; NHYA, new york heart association; $L V$, left ventricular.
\end{tabular}


TABLE 6. Comparison of mitral inflow velocities between patients with or without postoperative mortality

\begin{tabular}{lccc}
\hline & $\begin{array}{c}\text { Operative } \\
\text { mortality } \\
(-)(\mathbf{n}=\mathbf{3 4})\end{array}$ & $\begin{array}{c}\text { Operative } \\
\text { mortality } \\
(+)\end{array}$ & $\begin{array}{c}\boldsymbol{P} \text { value } \\
(\mathbf{n}=\mathbf{6})\end{array}$ \\
\hline E ins $(\mathrm{m} / \mathrm{s})$ & $0.76 \pm 0.30$ & $0.72 \pm 0.39$ & .78 \\
E exp (m/s) & $0.96 \pm 0.28$ & $1.02 \pm 0.43$ & .64 \\
A ins $(\mathrm{m} / \mathrm{s})$ & $0.30 \pm 0.28$ & $0.48 \pm 0.47$ & .25 \\
A exp (m/s) & $0.35 \pm 0.30$ & $0.45 \pm 0.41$ & .52 \\
DT ins (msec) & $125 \pm 35$ & $157 \pm 50$ & .09 \\
DT exp (msec) & $151 \pm 38$ & $172 \pm 46$ & .28 \\
Respiratory variation of E (\%) & $30 \pm 19$ & $51 \pm 35$ & .06 \\
\hline
\end{tabular}

$E$, Mitral early diastolic filling velocity; Ins, inspiration; Exp, expiration; $A$, mitral late diastolic filling velocity; $D T$, deceleration time of $\mathrm{E}$ wave.

patients ( 1 expected death and 1 unexpected death). Two cardiac-related deaths due to progressive $\mathrm{CHF}$ were each from group 1 and group 2 . All late deaths but 1 (sudden unexpected death) of group 3 were caused by noncardiac illness. The postoperative long-term survival of group 1 was significantly lower compared with that of groups 2 and 3 . The survival of groups 1 to 3 at 2 years was $45 \% \pm 14 \%, 69 \% \pm 15 \%$, and $81 \% \pm 10 \%$, respectively $(P=.008)$ (Figure 4$)$.

\section{DISCUSSION}

The present study shows that 1) a significant number of patients with $\mathrm{CP}$ had abnormal LV contractility and relaxation properties assessed by high-fidelity micromanometer catheter during cardiac catheterization; and that 2) patients with $\mathrm{CP}$ undergoing pericardiectomy who have abnormal LV contractility and relaxation properties before surgery, compared with those with normal LV contractility and relaxation properties, incur higher operative mortality and poor long-term outcome after surgery.

\section{Myocardial Function in Patients with Constrictive Pericarditis}

Because the fundamental abnormality in $\mathrm{CP}$ is the rigid encasement of the heart by thickened pericardium, the intrinsic myocardial function should be normal. However, the profile of $\mathrm{CP}$ has evolved in the current era. Patients are older

TABLE 7. Cardiac catheterization data between patients with or without postoperative mortality

\begin{tabular}{lccc}
\hline & $\begin{array}{c}\text { Operative } \\
\text { mortality } \\
(-)(\mathbf{n}=\mathbf{3 4})\end{array}$ & $\begin{array}{c}\text { Operative } \\
\text { mortality } \\
(+)(\mathbf{n}=\mathbf{6})\end{array}$ & $\begin{array}{c}\boldsymbol{P} \\
\text { value }\end{array}$ \\
\hline Mean RAP $(\mathrm{mm} \mathrm{Hg})$ & $21 \pm 6$ & $26 \pm 6$ & .1 \\
RVSP $(\mathrm{mm} \mathrm{Hg})$ & $47 \pm 11$ & $49 \pm 4$ & .56 \\
RVEDP $(\mathrm{mm} \mathrm{Hg})$ & $23 \pm 6$ & $29 \pm 6$ & .02 \\
PAWP $(\mathrm{mm} \mathrm{Hg})$ & $25 \pm 6$ & $31 \pm 10$ & .08 \\
LVSP $(\mathrm{mm} \mathrm{Hg})$ & $119 \pm 23$ & $123 \pm 27$ & .82 \\
LVEDP $(\mathrm{mm} \mathrm{Hg})$ & $25 \pm 6$ & $32 \pm 9$ & .05 \\
CI $\left(\mathrm{L} / \mathrm{min} / \mathrm{m}^{2}\right)$ & $2.6 \pm 1.2$ & $2.4 \pm 2.0$ & .25 \\
+dP/dt $(\mathrm{mm} \mathrm{Hg} / \mathrm{sec})$ & $1331 \pm 331$ & $1085 \pm 128$ & .08 \\
tau $(\mathrm{msec})$ & $55 \pm 17$ & $76 \pm 8$ & .007 \\
\hline
\end{tabular}

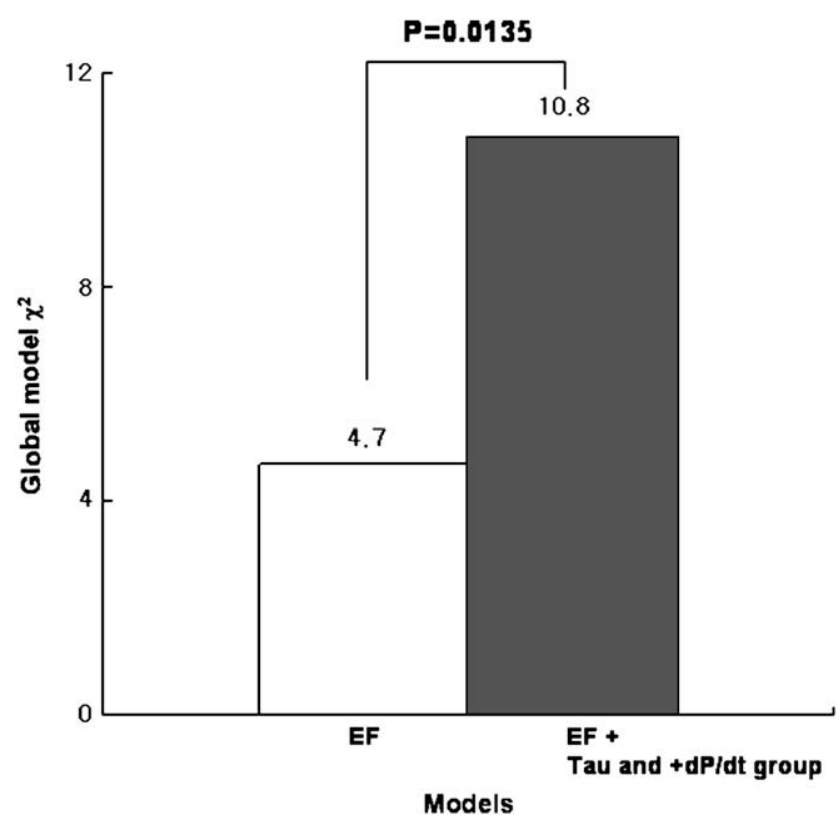

FIGURE 1. Incremental prognostic value of tau and $+\mathrm{dP} / \mathrm{dt}$ in models for prediction of postoperative mortality. The predictive power for operative mortality was improved significantly with the addition of non-ejection indexes of cardiac function $(+\mathrm{dP} / \mathrm{dt}$ and tau) to ejection fraction. $E F$, Ejection fraction.

with previous open surgery and mediastinal irradiation as more frequent causes of $\mathrm{CP},{ }^{6,16,17}$ which may result in abnormal LV relaxation or even contractility in these patients. The current study demonstrates that a significant number of patients with CP had abnormal LV contractility and relaxation properties assessed by high-fidelity micromanometer catheter during cardiac catheterization, and that these properties have a significant impact on immediate and longterm outcomes of patients with $\mathrm{CP}$ after pericardiectomy.

\section{Impact of Myocardial Function on Perioperative Mortality and Late Survival After Pericardiectomy}

A low-output syndrome occurs in $14 \%$ to $28 \%$ patients in the immediate postoperative period, and risk factors predictive of in-hospital mortality and low-output syndrome include the degree of preoperative disability (functional class III or IV) and severity of constriction as indicated by marked elevation of right ventricular end-diastolic pressure or right atrial pressure. ${ }^{2,5,6}$ McCaughan and colleagues ${ }^{2}$ suggested that poor hemodynamic results after complete pericardiectomy relates to the preoperative degree of constriction and resultant cardiomyopathy. Thus, early pericardiectomy would be recommended when $\mathrm{CP}$ is diagnosed. The results of our study were consistent with the previous study and extend the importance of myocardial function as a determinant of immediate outcome (in terms of mortality, hospital stay, need for inotropic support or intraaortic balloon pump, and postoperative renal dysfunction) of pericardiectomy. 


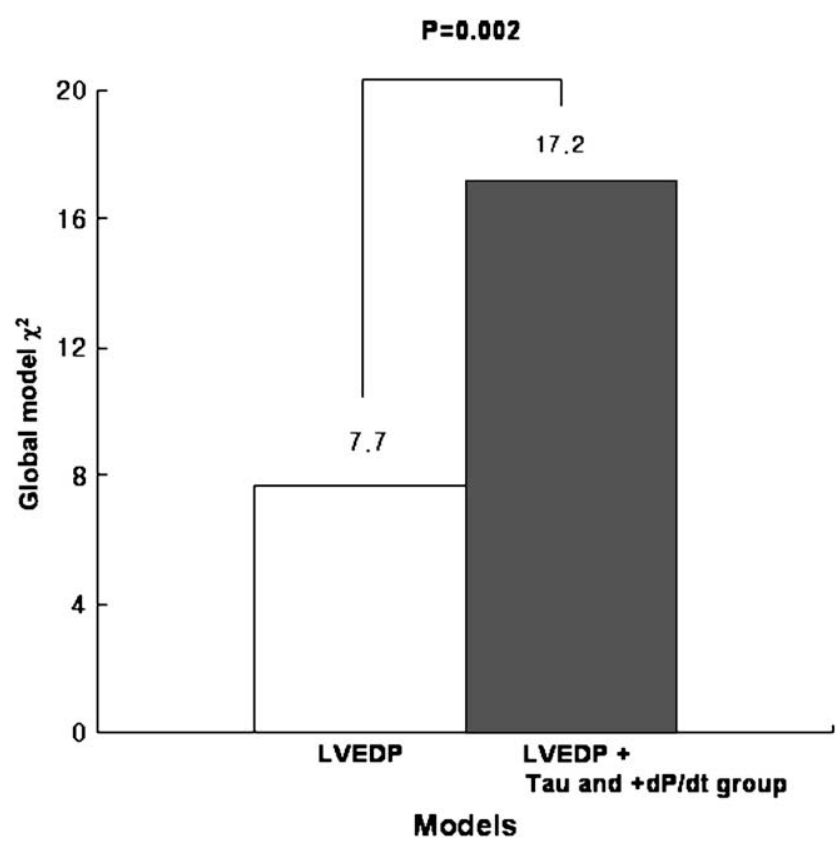

FIGURE 2. Incremental prognostic value of tau and $+\mathrm{dP} / \mathrm{dt}$ in models for prediction of postoperative mortality. The predictive power for operative mortality was improved significantly with the addition of non-ejection indexes of cardiac function $(+\mathrm{dP} / \mathrm{dt}$ and tau) to left ventricular end-diastolic pressure. $L V E D P$, Left ventricular end-diastolic pressure.

Despite the fact that the majority of patients had undergone radical surgery, approximately one third of patients experienced new or recurrent symptoms during follow-up. Long-term survival and symptomatic relief do not seem to be influenced by age, choice of median sternotomy or left thoracotomy, or transient low-output syndrome postoperatively. A previous investigation did show that clinical variables, such as age, NYHA class, and a radiation cause for $\mathrm{CP}$, are predictors of outcome after pericardiectomy. ${ }^{7}$ The overall outcome is unfavorably influenced by the presence of severe preoperative functional disability (NYHA class III or IV, diuretic use), renal insufficiency in the preoperative state, the presence of extensive nonresectable calcifications, incomplete pericardial resection, and the presence of radiation pericarditis, which is commonly complicated by myocardial fibrosis and restrictive myocardial disease. Thus, intrinsic myocardial property is the important determinant of postoperative outcome.

\section{Limitations}

The major limitation of this study is the retrospective nature of the study design. This study involved only patients who had preoperative cardiac catheterization with a micromanometer catheter. Therefore, most of the patients may have mixed features of $\mathrm{CP}$ and restrictive myocardial disease process. The profile of $\mathrm{CP}$ has evolved and older age, previous open surgery, and mediastinal irradiation have emerged as important causes of $\mathrm{CP}$; thus, the patients with $\mathrm{CP}$ in-

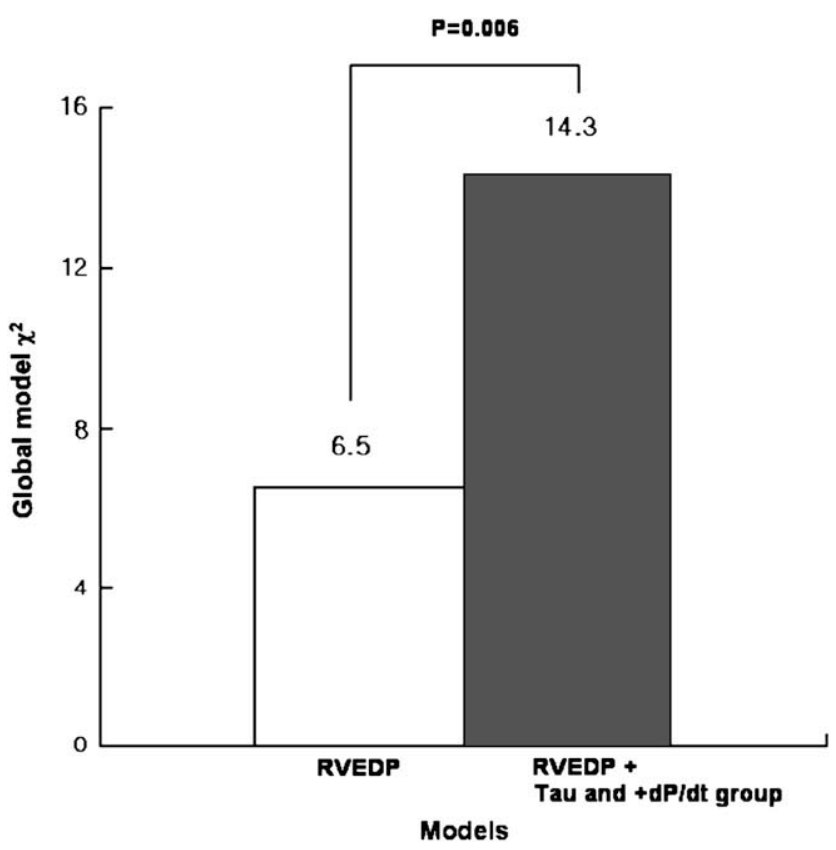

FIGURE 3. Incremental prognostic value of tau and $+\mathrm{dP} / \mathrm{dt}$ in models for prediction of postoperative mortality. The predictive power for operative mortality was improved significantly with the addition of non-ejection indexes of cardiac function $(+\mathrm{dP} / \mathrm{dt}$ and tau) to right ventricular end-diastolic pressure. $R V E D P$, Right ventricular end-diastolic pressure.

cluded in this study may be the most difficult subset of CP for diagnosis. The LV contractility and relaxation properties were assessed by the use of high-fidelity micromanometertipped catheters in this study. Although the measurement of $+\mathrm{dP} / \mathrm{dt}$ and tau remains the most accepted method for determining the rate of LV contraction and relaxation in humans, the widespread use has been limited because invasive and expensive high-fidelity, manometer-tipped catheters are required. A recent study demonstrated that examination of dynamic respiratory changes indicating increased ventricular interdependence may be helpful in the diagnosis of $\mathrm{CP}$ in the cardiac catheterization laboratory. ${ }^{18}$ The assessment of isovolumic indices of LV contractility and relaxation may add prognostic information, especially on operative mortality and subsequent CHF.

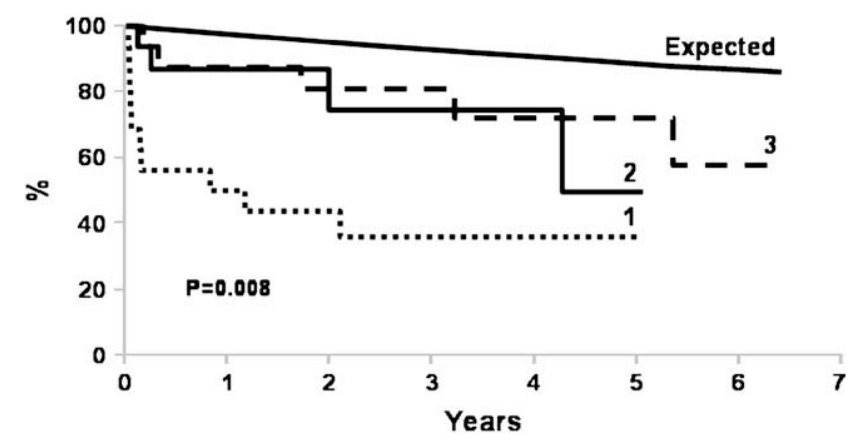

FIGURE 4. Comparison of survival between the 3 groups categorized by non-ejection indexes of cardiac function $(+\mathrm{dP} / \mathrm{dt}$ and tau). 


\section{Clinical Implications}

Although operative mortality has been reduced significantly, the immediate and long-term results of pericardiectomy are disappointing for some patients. The results of our study provide insight into using $+\mathrm{dP} / \mathrm{dt}$ and tau as a surrogate for selection and risk stratification of surgery in patients with CP. There were no noninvasive Doppler parameters that separated those who died versus those who lived. Because we have shown that LV contraction and relaxation properties are also important determinants of perioperative mortality and long-term outcome, patients with $\mathrm{CP}$ who are scheduled for pericardiectomy and have several high-risk clinical variables should be assessed for LV contraction and relaxation properties for better stratification of surgical risks. We believe the concept of "myopericardial disease" in patients with $\mathrm{CP}$ is important because the spectrum of $\mathrm{CP}$ has changed in the modern era.

\section{CONCLUSIONS}

In patients with $\mathrm{CP}$ who undergo pericardiectomy, those with abnormal LV contractility and relaxation properties assessed by cardiac catheterization before surgery incur higher operative mortality and poor long-term outcome after surgery. Evaluation of LV contractility and relaxation properties may be helpful for a risk assessment of pericardiectomy, especially for patients with several conventional risk factors for adverse outcome of surgery.

\section{References}

1. DeValeria PA, Baumgartner WA, Casale AS, Greene PS, Cameron DE, Gardner TJ, et al. Current indications, risks, and outcome after pericardiectomy. Ann Thorac Surg. 1991;52:219-24.
2. McCaughan BC, Schaff HV, Piehler JM, Danielson GK, Orszulak TA, Puga FJ, et al. Early and late results of pericardiectomy for constrictive pericarditis. J Thorac Cardiovasc Surg. 1985;89:340-50.

3. Tuna IC, Danielson GK. Surgical management of pericardial diseases. Cardiol Clin. 1990;8:683-96.

4. Stalpaert G, Suy R, Daenen W, Nevelsteen A. Total pericardectomy for chronic constrictive pericarditis: early and late results. Acta Chir Belg. 1981;80:277-82.

5. Tirilomis T, Unverdorben S, von der Emde J. Pericardiectomy for chronic constrictive pericarditis: risks and outcome. Eur J Cardiothorac Surg. 1994;8: 487-92.

6. Seifert FC, Miller DC, Oesterle SN, Oyer PE, Stinson EB, Shumway NE. Surgical treatment of constrictive pericarditis: analysis of outcome and diagnostic error. Circulation. 1985;72(suppl II):II-264-73.

7. Ling LH, Oh JK, Schaff HV, Danielson GK, Mahoney DW, Seward JB, et al. Constrictive pericarditis in the modern era: evolving clinical spectrum and impact on outcome after pericardiectomy. Circulation. 1999;100:1380-6.

8. Levine HD. Myocardial fibrosis in constrictive pericarditis: electrocardiographic and pathologic observations. Circulation. 1973;48:1268-81.

9. Paul O, Castleman B, White PD. Chronic constrictive pericarditis: a study of 53 cases. Am J Med Sci. 1948;216:361-77.

10. Roberts JT, Beck CS. Effect of chronic cardiac compression on size of heart muscle fibers. Am Heart J. 1941;22:314-20.

11. Dines DE, Edwards JE, Burchell HB. Myocardial atrophy in constrictive pericarditis. Proc Staff Meet Mayo Clin. 1958;33:93-9.

12. Hatle LK, Appleton CP, Popp RL. Differentiation of constrictive pericarditis and restrictive cardiomyopathy by Doppler echocardiography. Circulation. 1989;79: 357-70.

13. Oh JK, Hatle LK, Seward JB, Danielson GK, Schaff HV, Reeder GS, et al. Diagnostic role of Doppler echocardiography in constrictive pericarditis. J Am Coll Cardiol. 1994;23:154-62.

14. Nishimura RA, Schwartz RS, Holmes DRJ, Tajik AJ. Failure of calcium channe blockers to improve ventricular relaxation in humans. J Am Coll Cardiol. 1993; 21:182-8.

15. Hinkle LEJ, Thaler HT. Clinical classification of cardiac deaths. Circulation. 1982;65:457-64.

16. Schiavone WA. The changing etiology of constrictive pericarditis in a large referral center. Am J Cardiol. 1986;58:373-5.

17. Cameron J, Oesterle SN, Baldwin JC, Hancock EW. The etiologic spectrum of constrictive pericarditis. Am Heart J. 1987;113:354-60.

18. Hurrell DG, Nishimura RA, Higano ST, Appleton CP, Danielson GK Holmes DR Jr, Tajik AJ. Value of dynamic respiratory changes in left and right ventricular pressures for the diagnosis of constrictive pericarditis. Circulation 1996;93:2007-13. 